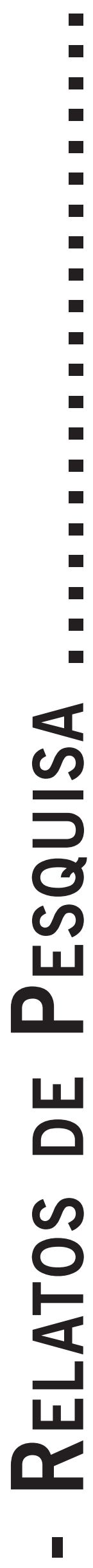




\title{
FENOMENOLOGIA DA PERCEPÇÃO EXTRACORPÓREA - ANÁLISE DE EXPERIÊNCIAS FORA DO CORPO
}

\author{
Phenomenology of Extracorporeal Perception - Analysis of Out-of-Body Experiences \\ Fenomenología de la Percepción Extracorpórea: Análisis de Experiencias Fuera del Cuerpo
}

Gabriel Teixeira de Medeiros

FERNANDO DE AlMEIDA SILVEIRA

\begin{abstract}
Resumo: Diversos autores apontam conceitos e etiologias para o fenômeno de Experiências Fora do Corpo (EFC). O presente artigo objetivou descrever e analisar as EFC a partir da experiência do vivido, elencando diferentes experiências denominadas EFC, comparando-as entre si e com o conceito científico de EFC, e investigando os sentidos dados a estas, bem como seu papel na vida cotidiana daqueles que alegam praticá-las, de modo a explorar as variedades de experiências rotuladas como EFC. Treze sujeitos foram entrevistados quanto a suas experiências, crenças e a consequência das EFC em suas vidas. Utilizou-se a análise de conteúdo, adotando Merleau-Ponty como principal referencial teórico para a interpretação dos dados. Os relatos de EFC foram divididos em dois grupos: aqueles que têm convicção da natureza espiritual destas - e que, assim, relataram experiências com presença de seres espirituais que os auxiliaram - e aqueles ressabiados de suas percepções - que se mantiveram céticos e, quando em EFC, permaneceram nos cômodos onde estavam fisicamente. Contudo, em ambos os casos, a experiência possuía um papel importante no entendimento e no modo de ser no mundo de tais sujeitos, sendo utilizada como coping para questões desde doenças crônicas, com risco de morte; ao desinteresse pela vida.
\end{abstract}

Palavras-chave: Fenomenologia; Corpo; Parapsicologia; Religião e psicologia.

\begin{abstract}
Several authors point out concepts and causes for the phenomenon of Out of Body Experiences (OBE). This article aimed to describe and analyze the OBE from the experience of the lived, listing different experiences called EFC, comparing them with each other and with the scientific concept of OBE, and investigating the meanings given to them, and their role in everyday life of those who claim to practice them in order to explore the variety of experiences named as OBE. Thirteen people were interviewed about their experiences, beliefs and consequence of OBE in their lives. We used content analysis, adopting Merleau-Ponty as the main theoretical framework for the interpretation of data. Reports of OBE were divided into two groups: those who have belief in the spiritual nature of such experiences - and thus reported experiences with the presence of spiritual beings who helped them - and those distrustful of their perceptions - who were skeptical and when in OBE, remained in the rooms where they were physically. However, in both cases, the experience had an important role in the understanding and being in the world of the experient, and is used as coping for questions from chronic diseases; life-threatening; to the lack of interest in life.
\end{abstract}

Keywords: Phenomenology; Body; Parapsychology; Religion and psychology.

Resumen: Varios autores señalan conceptos y las causas del fenómeno de Experiencias fuera del cuerpo (EFC). Este artículo tiene como objetivo describir y analizar el EFC de la experiencia de lo vivido, enumerando las diferentes experiencias llamadas EFC, comparándolos entre sí y con el concepto científico de EFC, y la investigación de los significados que se les da, así como su papel en la vida cotidiana de aquellos que dicen practicarlas; con el fin de explorar la variedad de experiencias etiquetadas como EFC. Fueron entrevistados trece sujetos acerca de sus experiencias, creencias y consecuencia de la EFC. Se utilizó el análisis de contenido, la adopción de Merleau-Ponty como el principal marco teórico para la interpretación de los datos. Informes de EFC se dividieron en dos grupos: aquellos que tienen fe en la naturaleza espiritual de estos - y por lo tanto las experiencias reportadas con la presencia de los seres espirituales que les ayudaron - y los que desconfían de su percepción - que eran escépticos y cuando en EFC, se quedaron en las habitaciones donde estaban físicamente. Sin embargo, en ambos casos, la experiencia tuvo un papel importante en la comprensión y ser en el mundo de tales sujetos, siendo utilizados como un afrontamiento para las cuestiones de las enfermedades crónicas, el riesgo de muerte; la falta de interés en la vida.

Palabras clave: Fenomenología; Cuerpo; Parasicología; Religión e psicología.

\section{Introdução}

O fenômeno de Experiência Fora do Corpo (EFC) refere-se à faculdade de toda percepção e/ou atuação além corpórea, ou aos estados alterados de consciência. Tais estados seriam inerentes aos seres humanos (Irwin, 1985) por meio do sono, meditação profunda, experiências de quase-morte
(EQM), traumas, estimulação elétrica do giro angular direito do cérebro, ilusões de óptica controladas, etc. (Blanke \& Arzy, 2005). A EFC é definida por Blackmore (1982) como "uma experiência na qual a pessoa parece perceber o mundo a partir de um local fora de seu corpo físico".

O estudo acerca das experiências fora do corpo toma forma no final do século XIX, e desde então, diversas fo- 
ram as abordagens ao tema. Os conceitos de espírito, dobro ou corpo sutil, como objeto que se desloca do corpo físico, foram utilizados como explicações de tais fenômenos por pesquisadores como Ernesto Bozzano e Frederic W. H. Myers, em sua obra inacabada e publicada postumamente, Human Personality and Its Survival of Bodily Death. Já em sua primeira página, Myers aponta a questão da existência de alma imortal ou de algum elemento da personalidade que possa sobreviver à morte física como a questão mais importante da humanidade. Embora na obra supracitada, o autor tenha considerado a maioria das manifestações mediúnicas oriundas do próprio médium, houve casos em que esta explicação não se mostrava suficiente. Nestes, Myers considerava como hipóteses mais plausíveis a telepatia e a comunicação de uma mente já desencarnada (Myers, 1903).

Em contraponto às ideias de dobro ou corpo sutil encontram-se outros pesquisadores e membros da Society for Psychical Research (SPR) - da qual Myers fazia parte - como Edmund Gurney, Podmore, Mrs. Sidgwick e Charles Richet, que consideraram tais fenômenos como alucinações ou meros sonhos. Hyslop (Alvarado, 1989), por sua vez, aceitou o componente extrassensório da experiência, mas atribuiu a sensação de EFC à tendência da mente subconsciente para dramatizar imagens de localidade que dão a impressão de que o evento se dava em uma diferente localização física.

Outros estudos, como é o caso dos de Charles Quartier (Osty, 1930), Penfield (1958) e, posteriormente Blanke, Ortigue, Landis e Seeck (2002), possuíam caráter psicofisiológico, atribuindo causalidade a estimulações cerebrais e estímulos físicos externos. Charles T. Tart (1968, 1976), por sua vez, inaugura uma era de estudos mais sofisticados, a partir do uso de EEG, no qual buscava avaliar as EFC de alguns sujeitos específicos que alegavam ter percepção extrassensorial durante suas EFCs.

As décadas de 1970 e 1980 foram marcadas por uma quantidade de pesquisas e de construções teóricas sem precedentes, com predomínio da abordagem psicológica em ambos os desenvolvimentos, conceitual e de pesquisa. Além disso, a primeira teoria EFC psicológica com previsões claramente testáveis foi apresentada. Resistem ideias de projeção de corpos sutis ou outros aspectos da personalidade como defendidas anteriormente por Myers e Bozzano, mas ainda em minoria. Esta também é a época em que são propostas as teorias psicológicas de Palmer; Blachmore e Irwin, sendo consideradas as ideias mais importantes do período.

Diversas teorias foram tecidas sobre os fenômenos de EFC. Tais hipóteses variam de alucinações a modelos psicológicos, chegando até a visão espírita e/ou espiritualista. Segundo John Palmer (1978), a EFC constitui-se como resposta a uma mudança da imagem corporal, causando uma ameaça à identidade individual, resolvida por meio de fantasias ou alucinações que teriam como intuito restabelecer a noção de self. Susan Blackmore (1984) sugere que as EFC são um modelo da realidade criada pelo organismo interno, usando recursos cognitivos quando os modelos dependentes na entrada sensorial foram interrompidos, de modo a retomar o controle sobre o meio externo.

Harvey J. Irwin (1985), por sua vez, enfatizou os processos cognitivos e de atenção como resposta para tal questão. Para ele, a EFC poderia ser patológica e relacionada com dissociação, ou não patológica, relacionada à absorção psicológica e propensão à fantasia. Seu modelo apresenta similaridades com o modelo de despersonalização de Whitlock (1978) e o modelo de dissociação em Spiegel \& Cardeña (1991).

Modelos cerebrais foram propostos, contudo, estes apresentavam locais de atividades cerebrais divergentes que se propunham responsáveis por tais fenômenos. Penfield (1958) localiza a "EFC” no córtex temporal, enquanto Blanke et al. (2002) apontam atividade no giro angular direito, e De Ridder, Van Laere, Dupon, Menovsky \& Van de Heyning (2007), sugerem estimulações parieto-temporais em pacientes com zumbido incurável como origem das referidas experiências. O modelo hemisférico de Persinger (1999), por sua vez, considera que uma alteração na percepção do self, devido a uma ativação do hemisfério esquerdo do cérebro, acompanhada de uma súbita desativação do hemisfério direito, possa gerar fenômenos de EFC ou déjà-vu; enquanto Wettach (2000) atribui a sensação de flutuar à atividade do mesencéfalo desacompanhada de uma orientação espacial normalmente fornecida por outras partes do sistema nervoso.

Tais resultados apresentam correlações positivas entre EFC e a incidência de estados alterados de consciência, estados dissociativos, capacidade de absorção, propensão à fantasia, bem como uma grande frequência em recordar sonhos comuns, experienciar sonhos lúcidos, apresentar sonhos vívidos, intensos e coloridos, vivenciar experiências místicas e experiências psíquicas.

Outra importante contribuição para o estudo das experiências fora do corpo foi proveniente das publicações do místico, filósofo, matemático e músico sul-africano Michael Whiteman (1980; 2006), que publicou cerca de 10.000 relatos de EFCs deliberadamente induzidas, contribuindo para a variedade de componentes místicos relativos à experiência supracitada, relevando as diferenças de percepção durante a experiência, enquanto experiências separativas ainda dentro do corpo; simultaneamente dentro e fora do corpo e àquelas situadas apenas fora do corpo.

O momento atual tem uma maior frequência de conceitos e pesquisas empíricas e, consequentemente, um aumento na publicação sobre EFC em parapsicologia e em revistas científicas de outras disciplinas. Este último desenvolvimento aponta para o despertar de um interesse de outras disciplinas sobre o tema, permitindo uma maior discussão e um maior entendimento do fenômeno, a partir de uma investigação interdisciplinar. Contudo, poucas foram as pesquisas que se focaram no caráter qualitativo de tais experiências. 
Outrossim, diversas pesquisas relativas às EFCs utilizaram apenas uma questão, baseada na questão de Palmer: Você já teve alguma experiência em que você sentiu como se se deslocasse "para fora" ou "para longe" de seu corpo, isto é, sentiu que sua consciência ou que sua mente estava em algum lugar diferente de seu corpo físico. Se estiver em dúvida se teve ou não esse tipo de experiência, porfavor, responda "não". Tal tipo de questão dificulta que respostas positivas apareçam quando há duas localidades para a consciência (dentro e fora do corpo) ou experiências que, embora ainda dentro do corpo, a pessoa sinta-se parcialmente fora do corpo, como no caso de algumas experiências descritas por Whiteman (2006).

Em contraponto, Alvarado (2004) afirma que a utilização de uma única questão de caráter dicotômico (sim ou não) impõe aos estudos uma carência de um relato qualitativo da experiência e permite uma superestimação da prevalência de tal fenômeno. Assim, o autor afirma existir evidências de queda na prevalência de EFC quando os pesquisadores aprofundam as questões, indo além dos questionários de múltipla escolha. Alvarado (2004) ainda chama atenção para a ambiguidade existente entre a EFC, sonhos e sonhos lúcidos, entre outras experiências anômalas; relevando as diferenças entre os sujeitos que tem uma sensação de estar localizados fora do corpo, daqueles em que tal separação não é clara. Assim, o autor aponta para a necessidade da inclusão da exteriorização do lócus de percepção, a fim de evitar tais ambiguidades.

Esta mesma tentativa de restringir o conceito de EFC, no intuito de minimizar os falsos positivos referentes à experiência foi defendida por Charles Tart (1975), que argumentou que a experiência deve ser real, de modo que a "consciência pareça completamente clara e normal" (p. 149). No entanto, tal definição ainda é bastante restritiva e subjetiva, de modo que as noções de "normal" ou "claro" não sejam igualmente partilhadas pelos pesquisadores, ou ainda, entre pesquisador e entrevistado.

Em face de tais questões, Neppe (2011) defende que o uso de uma única questão é insuficiente para o estudo das EFC. Ele ainda considera a existência de diferentes epifenômenos nomeados como experiências extracorpóreas, os quais possuem características fenomenológicas e etiologias distintas. Deste modo, releva a importância de entender as diversas formas de EFC e os diversos fenômenos a ela relacionados, a fim de entender suas diferenças e a adaptar os achados científicos a cada fenômeno específico.

O presente artigo visa o conteúdo do fenômeno enquanto experiência do vivido, de modo a explorar as variedades das experiências denominadas EFC, tendo como aporte teórico a fenomenologia de Maurice Merleau-Ponty. Merleau-Ponty (1942/2006) não conceberia a divisão entre psíquico e somático, pois não se trata de fatores exteriores um ao outro, mas o segundo integrando o primeiro: “(...) longe de meu corpo ser para mim apenas um fragmento de espaço, para mim não haveria espaço se eu não tivesse corpo" (Merleau-Ponty, 1945/2006, p. 149).
Tal corpo implica o agenciamento das qualidades perceptivas da consciência, o que pressupõe a indissociabilidade entre faculdades sensíveis e intelectuais. Admitir a experiência intelectual fora do corpo, segundo a fenomenologia de Merleau-Ponty, seria incorrer no mesmo equívoco cartesiano. A consciência perceptiva evoca num ato unívoco sensibilidade e reflexão, transformando o corpo em instrumento cognoscente. Desse modo, a experiência fora do corpo demanda um corpo para existir, pois apenas dele pode brotar a percepção:

Antes da ciência do corpo - que implica a relação com outrem -, a experiência de minha carne como ganga de minha percepção ensinou-me que a percepção não nasce em qualquer outro lugar, mas emerge no recesso de um corpo (Merleau-Ponty, 2003, p. 21).

Contudo, a partir da fenomenologia a questão não é a veracidade da percepção, mas ao contrário, considerar que "o mundo é aquilo que nós percebemos" (MerleauPonty, 1945/2006, p. 13-14). A fenomenologia, portanto, é o estudo das essências e trata de descrever os fenômenos, não de explicá-los ou analisá-los, pois tal "explicação não é descoberta mas inventada, ela nunca é dada com o fato, é sempre uma interpretação provável” (p. 165), "e tudo o que vivemos ou pensamos sempre tem vários sentidos" (p. 233). Ademais, no intuito de explorar a gama de fenômenos nomeados EFC, este estudo não se foca na questão ontológica ou etiológica da experiência fora do corpo, mas na experiência percebida de tal fenômeno e no sentido a esta atribuída.

Pois, como aponta Merleau-Ponty, o homem interior não existe, o homem está no mundo, é no mundo que ele se conhece. Dessa forma, seja o fenômeno anômalo um fenômeno real ou apenas uma experiência subjetiva, enquanto vivido, confere ao ser aquilo com o que este se configurará diante do mundo. "O mundo fenomenológico não é a explicitação de um ser prévio, mas a fundação do ser; a filosofia não é o reflexo de uma verdade prévia, mas assim como a arte, é a realização de uma verdade" (Merleau-Ponty, 1945/2006, p. 19).

\section{Objetivos}

Descrever as experiências denominadas EFC por aqueles que alegam praticá-las, descrevendo o sentido dado à experiência e seu papel social na vida do sujeito; identificar padrões de relato e estruturas de significação na EFC; e contrastar a denominação científica de EFC e as experiências apresentadas pelos sujeitos que alegam praticá-las.

\section{Metodologia}

Uma abordagem qualitativa foi utilizada, por meio de entrevistas semiestruturadas. O número total de partici- 
pantes não foi decido a priori, mas determinado ao longo da coleta de dados, por meio do critério de saturação (Patton, 1990). Treze pessoas que alegaram ter passado por, ao menos uma EFC, foram entrevistadas. A seleção dos sujeitos foi aleatória, tendo como critérios de exclusão: a) possuir um diagnóstico psiquiátrico de psicose - este obtido por meio de uma questão única e direta ao entrevistado; b) ter vivenciado a EFC sob efeito de algum composto alucinógeno; e, c) possuir idade inferior a 18 anos. A metodologia escolhida para acessar tais sujeitos foi a bola de neve (snowball ou chain sampling), tal método consiste na identificação de sujeitos que atendam aos critérios para a pesquisa e aceita participar da mesma, aos quais será questionado sobre outras pessoas que possam fazer parte da pesquisa. Assim, tal qual uma bola de neve, a amostra tende a tornar-se maior e maior a cada novo informante até contemplar o critério de saturação (Patton, 1990).

A escolha deste método se justifica pela dificuldade de encontrar pessoas que afirmem ter EFC. Assim, o método bola de neve é escolhido por poder acessar as redes de sujeitos que apresentam tais fenômenos. O ponto inicial da bola de neve foram os estudantes da UNIFESP Campus Baixada Santista que alegavam tais experiências, estendendo-se para suas indicações de novos potenciais entrevistados. Em um primeiro contato, era perguntado ao possível entrevistado se este entendia ter experienciado uma EFC, sem uso de qualquer substância alteradora de consciência, e quanto a possuir diagnóstico de psicose. Satisfeitos tais requisitos, a entrevista era agendada. O estudo foi aprovado pelo Comitê de Ética em Pesquisa - Plataforma Brasil, sob o parecer número 142.729, de 01 de novembro de 2012.

Todos foram entrevistados de forma individual e sigilosa, após leitura e concordância com o Termo de Consentimento Livre e Esclarecido. As entrevistas ocorreram no laboratório de pesquisa social da UNIFESP - Campus Baixada Santista. Caso da impossibilidade do entrevistado em dirigir-se até a universidade, este pudia solicitar que a entrevista ocorresse em outro lugar, desde que satisfeitos os critérios de sigilo e segurança, constando de um espaço adequado, em que se encontrassem apenas entrevistado e entrevistador (Patton, 1990).

A entrevista se baseou na descrição pormenorizada da experiência que o sujeito atribuísse ser EFC e de seus desdobramentos na vida do sujeito a partir dos sentidos dados por este, acerca do fenômeno; na tentativa de observar a experiência fora do corpo como ela se mostra, para cada entrevistado. De modo que fenômeno e sentidos se encontram imbricados no mesmo ato, seja porque, a despeito das propriedades do próprio objeto, o fenômeno existe apenas "em função daquele que o observa e, nessa visada, lhe atribui sentido" (Freitas; Araújo; Franca; Pereira \& Martins, 2012, p. 144-154); ou seja, na concepção de percepção enquanto uma interpretação. Assim, nas palavras de Merleau-Ponty (1945/2006) "Compreendida a percepção como interpretação, a sensação, que serviu de ponto de partida, está definitivamente ultrapassada, qualquer consciência perceptiva já estando para além dela” (p. 66).

As entrevistas foram gravadas, após a autorização dos entrevistados, e, posteriormente, realizou-se sua transcrição literal, visando à análise. Para a análise, foi utilizada a análise de conteúdo, que permite emergir "núcleos de sentido" extraídos dos relatos dos participantes, por meio de orações expressivas de um discurso em relação ao tema investigado e sua relação com os demais entrevistados. Assim, as entrevistas forma realizadas, transcritas e analisadas inicialmente, de modo a descrever o fenômeno vivido por cada entrevistado. Após esta primeira etapa, uma segunda análise da entrevista foi feita, relevando e listando todas as categorias encontradas em cada entrevista (Moustakas, 1994).

Estas categorias foram arranjadas em grupos de unidades de sentido, os quais nortearam a construção de duas descrições, uma sobre o quê fora vivenciado como EFC e outra sobre como tal fenômeno ocorreu. Ao fim das etapas supracitadas, um último escrito foi composto, de modo a incorporar ambas as descrições, a fim de descrever a experiência vivida por cada entrevistado (Creswell, 2012).

Esta técnica permitiu que dados brutos (falas dos participantes) fossem transformados e agregados, de forma organizada, em unidades de sentido, a partir da definição criteriosa de seus núcleos, tendo a fenomenologia merleau-pontyana como referência de interpretação. Assim, a partir do método fenomenológico, foi proposta a ordem de análise a partir da experiência humana, seguida de sua legitimação (seja pelo próprio sujeito, seja pelo campo de saber que estuda tais fenômenos) e, por fim, da análise que constrói sentido àquele que vivencia EFC (Gomes, 2010).

Deste modo, a análise buscou se fixar, primeiramente, na experiência relatada por cada entrevistado, não buscando igualá-la às demais, mas sim encontrar diálogos entre as diferentes EFC, "pois nomear um objeto é afastar-se do que ele tem de individual e de único para ver nele o representante de uma essência ou de uma categoria" (Merleau-Ponty, 1945/2006, p. 239-240).

Observação: A fim de manter o anonimato dos entrevistados, seus nomes foram substituídos por nomes fictícios, seguidos de suas idades (e.g. Joana/22). A escolaridade foi suprimida, devido a todos os entrevistados apresentarem, como escolaridade mínima, ensino superior incompleto.

\section{Resultados}

Os relatos analisados foram divididos didaticamente em dois grupos, um com uma maior tendência ao viés de caráter espiritual das EFC e outro com uma maior tendência ao viés de caráter psicológico da referida experiência. Contudo, tais diferenças se referem, predominantemente, ao sentido dado às experiências e não ao conteúdo, propriamente dito. Estes grupos serviriam para ilustrar duas grandes categorias, mais do que, de fato, agrupar e defi- 
nir tais sujeitos que apresentam seus discursos em uma gradação entre estas duas categorias. Deste modo, tais categorias, aquém de serem exatamente grupos estanques, são referenciais para análise.

Assim, serão apresentados, primeiramente, o conceito de EFC e os relatos da experiência, para depois, apresentar as diferenciações e agrupamentos dos resultados, a partir do sentido dado à experiência.

\section{Experiência fora do corpo}

A experiência fora do corpo é a experiência na qual o sujeito sente a si mesmo ou o centro de sua consciência localizado fora de seu corpo. Frequentemente envolve sensação de flutuação fora do corpo, observação do próprio corpo de um local externo a este (autoscopia) e viagens a localizações distantes. Embora a EFC possa ocorrer em sono ou vigília e alguns trabalhos apresentarem, inclusive, relatos de EFC durante atividade física ou durante atividades comuns da vida diária (Alvarado, 2004; De Foe, 2012), apenas uma entrevistada relatou ter tido a experiência acordada, enquanto estava de pé. Todas as demais experiências são relatadas ocorrendo durante o sono ou em período crepuscular, entre a vigília e o sono, quando tentavam dormir.

Joana/22 estava de pé, abraçada com o namorado quando começou a se sentir fraca:

Aí... eu fui pra casa do Raul [namorado]. E a gente tava assim, na sala, normal. [...] E eu não sei explicar, a gente tava perto assim, e a gente se abraçou. Do nada. E aí eu comecei a ver tudo ficar branco. Branco, branco, branco, branco. [...] É, então, mas... começou a tudo ficar branco, e aí é como se eu já não tivesse mais no meu corpo. Eu comecei a ficar... eu lembro que eu comecei a ficar fraca. Sabe, de tremer, assim, de como se a pressão tivesse baixando? E eu percebia que ele também tava na mesma sintonia que eu. E a gente foi pra um lugar, muito claro, muito claro (Joana/22).

Além de Joana/22, Jéssica/22 e Ricardo/24 relatam ter tomado consciência em suas experiências, em local diferente de onde seus corpos estavam e desconhecido para eles.

Eu não consegui entender o que foi essa experiência. É... eu tava... eu fui pra um lugar, assim, com umas montanhas... Tudo era, tipo, marrom clarinho, sabe, umas pedras assim [...] (Jéssica/24).

Aí, quando eu acordei, eu acordei consciente já, num outro lugar, assim. Eu acordei, eu tava numa espécie de ruínas, assim, ruínas de prédio e... não era... não era um lugar que eu conhe... [...] fisicamente, assim, não era um lugar que eu conhecia (Ricardo/24).
Letícia/30 relata algo semelhante, mas diz que o local onde se encontrava, durante a experiência, parecia um túnel que conhecia e usava com alguma frequência, quando ainda morava no Rio de Janeiro. Sua experiência ocorreu poucos meses após ter retornado para a casa dos pais, no interior de São Paulo. Já no caso de Melissa/23 e Rodolfo/24, embora não iniciem a experiência no cômodo em que seus corpos se encontram, esta ainda ocorre em suas casas, ou seja, próximo de seus corpos e em local conhecido. Entretanto, na experiência de Melissa/23, sua casa é uma pouco modificada, o que mesmo para ela foi um sinal de que era um sonho:

Eu tava em casa e tinha uma... uma torneira onde saia muita água, lá na... lá na minha sala, sala da minha casa, lá em São Paulo. Então, é... aí... e tinha vários jovens e eu tava nadando... conversava, tinha familiares meus, também, pessoas... jovens, mesmo, adolescentes que eu desconhecia. Mas eu conversava e eu nadava toda hora, ficava nadando, nadando, nadando... (Melissa/23).

É só após acordar e conversar com seu pai que Melissa/23 interpreta sua experiência como EFC. Este sentido dado à experiência será discutido mais abaixo. No caso dos sete entrevistados restantes, todos narram o início de suas experiências no mesmo cômodo que seus corpos estavam. Aline/26 e Rafael/38 relatam apenas uma sensação de desligar-se do corpo e flutuação, próximo ao teto, como relata $\mathrm{Rafael} / 38$ :

É, porque na verdade... eu... eu via a cama, eu sentia a sensação de estar deitado. Sabe a sensação de estar deitado na cama? Eu senti mas, ao mesmo tempo, eu senti indo pro teto, subindo. Como se fosse inflando. Engraçado, parece que inflou. É verdade, agora eu to... tá ficando mais claro pra mim. Inflou. Quando eu vi, eu olhei pra baixo, eu tava deitado. [...] Quando eu virei e olhei, aí eu cai (Rafael/38).

Mateus/35, Flávia/33, Bárbara/31 e Marcela/23 relatam ter autoscopia, assim que se percebem fora do corpo. Flávia/33 e Marcela/33 dizem observar seus corpos de cima, próximas ao teto e sem mobilidade, permanecendo no mesmo local até o fim da experiência, mas aptas a olhar todo o cômodo. Já Mateus/35 e Bárbara/31 descrevem sensação de flutuação, mas próximos ao chão e se locomovem por todo o quarto. Estela/70 também flutua próximo ao chão e pode se locomover, mas não fica apenas em seu quarto, transitando por toda sua casa. Ela é a única que relata ter acompanhado a saída do corpo, contudo, diz não ter olhado para seu próprio corpo, neste momento; tendo o visto apenas próximo ao fim da experiência, quando retorna ao corpo.

Assim como Estela/70, Joana/22 também diz ver seu corpo no retorno de sua experiência, como relata a seguir: 
E aí, a gente volta. E nisso que a gente volta, tipo... é... isso mesmo, como se eu fosse tremendo até voltar... Mas não, antes disso [...] É como se eu tivesse em cima da cozinha, olhando a gente abraçados... (Joana/22).

Os dados apresentados apontam para uma diversidade de fenômenos considerados EFC. Em que pese à definição científica controvérsias sobre o que seria EFC, as experiências relatadas apresentam a mesma controvérsia e bastante pluralidade, algumas se aproximando, inclusive, da definição de sonho lúcido, ou mesmo conteúdo onírico comum. O que confere a tais experiências o caráter de EFC é dado pelo sentido da experiência do vivido, o qual, segundo Merleau-Ponty (1945/2006);

Em um acontecimento considerado de perto, no momento em que é vivido, tudo parece caminhar ao acaso [...] Mas os acasos se compensam e eis que essa poeira de fatos se aglomera, [...] desenha um acontecimento cujos contornos são definidos e do qual se pode falar. Deve-se compreender a história a partir da ideologia, ou a partir da política, ou a partir da religião, ou então a partir da economia? [...] Todas essas visões são verdadeiras, sob a condição de que não as isolemos, de que caminhemos até o fundo da história e encontremos o núcleo único de significação existencial que se explicita em cada perspectiva (p. 17).

\section{0 sentido da experiência}

Com base nas tendências atuais sobre a interpretação das EFC, tal fenômeno é entendido, em sua maioria das vezes, enquanto uma experiência psicológica, não resistindo o conceito de duplo ou um espírito que de fato saia do corpo. Assim, tal fenômeno, apesar de anômalo não é considerado como fenômeno de percepção extrassensória, embora, na experiência do vivido, seja relatado enquanto real e, deste modo, entendido, de fato, enquanto uma experiência externa ao corpo.

Para a fenomenologia merleau-pontyana, tal experiência também é entendida por seu viés psicológico, pois o autor critica o binômio corpo/alma, enquanto definido de modo a entender a alma como instância autônoma que age sobre o corpo, pois “é supor erroneamente uma noção unívoca do corpo e sobrepor-lhe uma segunda força que dá conta do significado espiritual de certas condutas". Deste modo, apresenta tal configuração de corpo e alma enquanto funcionamento integrado "num nível superior, ao funcionamento da vida", no qual "corpo se tornou de fato corpo humano” (Merleau-Ponty, 1942/2006, p. 312).

Deste modo, tomando por base a obra de Merleau-Ponty (1945/2006), a EFC se configuraria, primeiramente, enquanto alucinação do corpo próprio, não estando a alucinação no mundo, “mas ‘diante’ dele, porque o corpo alucinado perdeu sua inserção no sistema das aparências" (p. 455). Contudo, quanto ao sentido dado à experiência, a EFC se constitui para além da noção ontológica, pois é o "testemunho desse movimento", de modo que "o fenômeno só existe em ato". Assim, "suas propriedades não são restritas ao objeto em si mesmo, mas só existem em função daquele que o observa e, nessa visada, lhe atribui sentido" (Freitas et al., 2012, p. 146).

Assim, a EFC para além de ter um significado, ela é, em si, o significado, como aponta Merleau-Ponty (1942/2006):

Com as fórmulas simbólicas, surge uma conduta que exprime o estímulo por si mesmo, que se abre para a verdade e para o valor próprio das coisas, que tende à adequação do significante e do significado, da intenção e daquilo a que ela visa. Aqui o comportamento não tem mais apenas um significado, é ele mesmo significado (p. 192-3).

Portanto, as diferentes gradações de entendimento quanto a uma real saída do corpo, bem como os argumentos e aspectos utilizados para sustentar tal experiência e o papel desta na vida do sujeito podem dar maiores esclarecimentos quanto às tendências no entendimento das EFC, por seus experienciadores.

Dentre as experiências em que não houve autoscopia e nas quais os sujeitos já se encontram em locais diferentes de seus corpos, no início da EFC, destaca-se a existência de outras pessoas, na experiência, as quais são entendidas como seres espirituais e que, juntamente com a vivacidade da experiência, corroboram para a definição de EFC em suas experiências.

Assim, tais experiências se definem por seu alto teor espiritual/religioso, sendo muitas vezes entendida como mediunidade e trazendo, em diversas vezes, conteúdos morais, como a necessidade da prática da caridade ou mesmo entendendo a EFC como forma de praticá-la.

Quando você começar a entender o que é, o que acontece e tal... e começar a trabalhar e ver que você tem que servir, né, você assumiu um compromisso. É uma mediunidade de trabalho, não é uma mediunidade natural, é de trabalho... (Letícia/30).

A presença de seres espirituais durante a EFC ou anterior ou posteriormente à experiência é descrita por Estela/70, Jéssica/24, Joana/22, Letícia/30, Rafael/38 e Ricardo/24. Tal presença espiritual é fator importante para a definição da experiência enquanto EFC:

Aí foi aí que eu vi, que eu acordei assustado e eu ouvi um a... um assobio [...] que me... me indicava e alguma coisa me resgatou na memória que era um apito de perigo. Isso. Aí quan... eu ouço um assobio assim, aí eu acordo assustado... achando que é alguma coisa, né, de ruim acontecendo. [...] Quando eu acordo e levanto da cama e olho pra parede. Aí eu vejo uma... uma... um 
ser... é... sumindo, enfim... foi pro teto. Como se fosse alguém com um manto... esvoaçante, dentro de um quadrado, subindo e... e desaparecendo em cima do teto. [...] Isso. Isso, é.... E que eu tive, na verdade, né? A ideia é que eu tive a visão de alguém, de uma entidade. De um ser. Que eu não sabia muito bem o que era. Aí eu associei aquilo a um ser que veio me acompanhar porque eu tava num momento de transição, né? (Rafael/38).

Já Estela/70, relata que a presença de um espírito fora crucial para sua EFC, não apenas em sua determinação, mas, segundo ela, para que pudesse sair do corpo:

Do pescoço pra cima tava muito colado na cabeça. A paracabeça não saia, não descolava. A cabeça do psicossoma não se descolava da cabeça, né? Mas tudo isso é o amparador que fez, que é pra eu ver passo-apasso, né, como é que eu posso sair. Eu sei que ele fez, mas eu só percebi depois, né? Eu tava achando que era eu, que era coisa minha, né? (Estela/70).

Outro aspecto importante, neste grupo, para a consideração de experiência fora do corpo, foram acontecimentos posteriores à experiência que pudessem, sob o entendimento dos sujeitos, comprovar a experiência. Assim, Joana/22, diz que em sua experiência, um espírito passava a mão em sua barriga e dizia que ela estava preparada:

Eu acredito que foi uma mensagem... pra falar... porque depois disso, eu tive uma sensação de que a qualquer momento eu ia ficar grávida. Qualquer momento eu tava só esperando, não sei explicar. Quando eu soube que eu tava grávida, não foi surpresa, eu sabia que eu tava grávida (Joana/22).

Já no caso de Melissa/23, a comprovação veio por parte de seu pai. Ela, até o momento achava estar sonhando e, após o ocorrido, questiona, inclusive, se outros "sonhos" não poderiam ser EFC que ela não entendeu:

Eu só considerei porque meu pai... eu tava na cama, ainda, tipo, eu tive a projeção, que pra mim era um sonho, porque não tinha nexo... enfim, eu tava fazendo... meu, só andando e outra hora eu queria usar o banheiro, enfim, são coisas que eu acho que não tem muito nexo. Então, quando eu acordei, isso tudo no sonho, entre aspas, né? Quando eu acordei, isso pra mim era um sonho, mas meu pai logo em seguida chegou na porta do meu quarto e perguntou, ele perguntou se eu tinha sonhado com água. E eu não costumo sonhar com água, eu não sonho com água. E bem nesse dia ele perguntou e falou que toda hora queria me ver. Enfim, foi isso... Por conta dele me falar que eu falei “ah, então foi uma projeção”. Aí eu falei, caramba, o que que é projeção, o que é sonho? Como diferenciar? Se meu pai não falasse, eu não ia saber (Melissa/23).
É relevante ressaltar que os entrevistados deste grupo apresentaram todos, como religião, o Espiritismo, a Umbanda ou o estudo da Conscienciologia, mas com forte influência espírita.

Flávia/33 afirma que sua experiência lhe pareceu muito real e concreta, se encontrando apenas em seu quarto. Contudo, a presença de seu falecido avô, na experiência descrita como sendo sua única EFC, dá a ela um caráter mais espiritual. No entanto, quando da experiência, Flávia/33, que era muito ligada ao avô, mas pouco interessada em qualquer tipo de religiosidade, considerando-se, inclusive, ateia; reconhece, na época, tal experiência apenas como uma oportunidade de se despedir de seu avô, sem qualquer definição sobre o que fora a experiência ou se seu avô estava de fato em sua experiência ou se tal experiência se caracterizava por uma representação subjetiva e psicológica de despedida de seu avô.

É apenas a partir de sua entrada na Umbanda que Flávia/33 entenderá tal experiência - ocorrida, cerca de, 15 anos antes - enquanto uma EFC. "Isso tinha acontecido, mas eu nunca tinha colocado pra mim mesma dessa forma; que tinha sido uma experiência fora do corpo" (Flávia/33).

Contudo, tendo sua incursão religiosa ocorrido há pouco tempo, Flávia/33 parece ter uma relação menos central com a EFC e seu entendimento da relação com o avô parece ter nuances mais mnemônicos e psicológicos do que uma relação espiritual.

Eu sinto que... é... da minha família, ele passou o bastão pra mim, entendeu? Sabe? E, de alguma maneiraeu pensei nisso esses dias - que enquanto eu viver, ele vive também. Sabe? É... então, em ocasiões familiares importantes, eu tenho feito discursos e meus discursos sempre envolvem [risos]... ah... o meu avô. E... e, enfim, coisas... coisas assim, né? Que eu sinto a gente conectado (Flávia/33).

Rodolfo/24, assim como Estela/70 e Melissa/23, também estuda a Conscienciologia, mas tem um entendimento mais psicológico da EFC, entendendo-a por seu caráter de consciência e lucidez. Assim, divide sonho, sonho lúcido e EFC de modo que:

Sonho é onirismo puro. Né? Imaginação total. Sonho lúcido é você estar mais ou menos descoincidido, mas ainda tem uma carga onírica naquilo. Então, você tem uma percepção projetiva, mas você tá influenciado pela sua imaginação e pelo seu onirismo, então as coisas se misturam e sua lucidez não é boa. [...] Aí a gente costuma dizer que a sua lucidez, nesse caso, numa escala de 0 a 100 seria 40\%. Aí, a projeção, você consegue dizer que é uma projeção quando você tá numa escala de lucidez de 60 a 100\%. Entendeu? Então, eu digo que é a projeção quando eu to nessa escala de lucidez. Então, nesse caso que eu te falei, o meu nível de lucidez tava por volta de $80 \%$ (Rodolfo/24). 
Mateus/35, que afirma não ter religião, também entende a experiência a partir de uma lucidez, durante a experiência e busca comprovações da EFC em dados concretos:

Eu já fiquei consciente estando, mais ou menos, ali acima do beliche, da parte de cima, superior. Tem duas partes, tem o de baixo e o de cima. O de cima, tinha uma... uma... tinha uma tesoura aberta, em determinado ângulo, acho que era, devia ser $45^{\circ}[. .$.$] e eu vi$ uns símbolos que tinham no lençol [...] Então quando eu vi os símbolos e quando eu vi a tesoura, eu já me questionei na hora. Assim, poxa, essa pode ser uma prova da... no momento que eu tinha saído do corpo, né? Eu me questionei naquele mesmo momento. Essa pode ser uma prova de que se eu to... se eu to ficando maluco ou se realmente eu consegui sair. Porque naquele momento eu já pensei tudo, eu falei assim "cara, eu nunca parei pra olhar o que tem em cima da... do... do... desse beliche, aqui, há se... há... semanas, pelo menos. Né? Como é que eu vou me lembrar da tesoura e do símbolo e pra onde ela tá virada? (Mateus/35).

Para ele a EFC está intimamente ligada ao sonho, sendo difícil diferenciar uma da outra, como aponta a seguir:

Isso, eu acho que foi uma das provas, né? Mas tem muita coisa que acaba podendo se fundir com esse lado e que é sonho, realmente. Então, eu acho que é assim, é muito difícil você conseguir... é... talvez, encontrar alguém que consiga, realmente, transitar por esses... por esses níveis mentais sem tropeçar em algum outro (Mateus/35).

Marcela/23 afirma ter constantemente tais tipos de experiências e as associa estritamente com um distúrbio de percepção e com um estado cataléptico de paralisia noturna (sobre paralisia noturna ver Holt, Simmonds-Moore, Luke \& French, 2012). Tal qual para Márcio, seu maior interesse nas EFC é a comprovação quanto à natureza de tal experiência, não apresentando nenhum fascínio sobre as experiências ou seus conteúdos.

Não, eu fico olhando pra televisão e... acho que eu cheguei a olhar pra mim de novo, assim. Mas, só, caramba, eu to aqui de cima e me vendo e to vendo televisão. Como é que pode? Entendeu? Mais questionando ali aquel... a... aquela situação, né? Mas mais prestando atenção na TV pra poder comparar depois, na hora que eu voltasse... (Marcela/23).

Bárbara/31 também afirma ter EFC constantemente e associadas à paralisia noturna. Ambas, juntamente com Mateus/35 e Rodolfo/24 relatam as EFC mais concretas e próximas do mundo conhecido por eles e habitado por seus corpos, não apresentando outros planos ou seres espirituais.

Todavia, diferentemente dos demais, Bárbara/31 entende a experiência enquanto a saída de sua alma, o que a aproxima do grupo com viés espiritual. No entanto, sua experiência se difere das demais com viés espiritual, seja pelo conteúdo mais concreto e sem entes espirituais, seja por sua relação com a experiência, a qual sente medo e não tem interesse em tê-la. De fato, Bárbara/31 teme morrer, durante a experiência, uma vez que se entende com a alma para fora do corpo. É importante frisar que Bárbara/31 é a única entrevistada que afirma ter mais de uma religião, se considerando espírita, umbandista e católica. Em que pese tais religiões possuírem epistemes diferentes e entendimentos divergentes sobre a experiência, tal dado parece ser importante para entender sua relação com a experiência, embora não a tornando clara.

\section{0 papel da experiência na vida de seus experien- ciadores}

Em que pese, à experiência, todo o sentido dado à mesma, é em seu sentido que reside, portanto, a experiência do vivido. Deste modo, a EFC vivida pelo sujeito, a despeito de sua verdade, implica o sujeito em toda a vivência desta, assim como Merleau-Ponty (1945/2006) aponta para a própria vivência do sonho:

Quando sonho que voo ou que caio, todo o sentido desse sonho está contido nesse voo ou nessa queda, se eu não os reduzo à sua aparência física no mundo da vigília, e se os considero com todas as suas implicações existenciais (p. 383).

Deste modo, tal experiência se inscreve junto às diversas outras experiências (corporais) do sujeito que alega sair do corpo. O papel desta experiência, dentre os sujeitos entrevistados, apresenta uma grande relevância, sobretudo, aos sujeitos apresentados como tendo maior viés espiritual. A EFC, para estes, apresenta grande importância em diversos outros entendimentos de suas vidas. É o caso da redução do medo da morte (tanatofobia), apresentada por Letícia/30, Ricardo/24, Melissa/23, Aline/26 e Estela/70.

Dentre estes, dois casos se destacam pela alta relevância do sentido dado à EFC e seu papel na vida do sujeito. Estela/70, tem câncer e diz que sua crença, suas experiências e o auxílio que recebe de entes espirituais a auxiliaram na aceitação e na luta contra a doença. Segundo ela:

Eu me manifesto nesse corpo, que já tá com uma certa idade, que tem um câncer. E não sei quanto tempo eu tenho, talvez não muito, né? Quem tem metástase não deve ter muito expectativa de vida. Antes de ter essas experiências, e principalmente dessa experiência que eu acabo de narrar pra você [...] eu tinha medo. Eu tinha medo da doença, do sofrimento e da morte, né? Apesar de eu ser espírita, trabalhava numa casa espírita, mas eu tinha medo. [...] E então, essas experiências fora do corpo, com lucidez, me ajudaram a perder o medo da morte. E por isso que hoje eu enfrento essa doença, né? [...] eu não tenho depressão, eu não... eu 
não tenho medo do que... nada. Eu... eu to... eu vivo, normal. Vivo melhor do que antes. Então, eu ganhei nisso, ganhei em termos de perder o medo da morte, porque pra mim, essas experiências fora do corpo me deram certeza de que a vida continua (Estela/70).

Como no caso dela, Ricardo/24 afirma que a EFC e os sentidos suscitados por ela auxiliaram-no quanto ao seu desinteresse pela vida, durante um momento de sofrimento psíquico:

Comecei a ver um sentido maior, assim, na vida. Um sentido... eu tive... tive uma fase meio difícil na adolescência, de... de querer me matar e tal, e não ver sentido em nada. E aí essas coisas trouxeram um... um sentido maior pra mim, sabe? (Ricardo/24).

Outras implicações descritas pelos entrevistados com viés mais espiritual foram: alteração da percepção do mundo, dizendo ter uma sensação de pequenez quanto à imensidão do universo; maior paciência, calma e comprometimento com o próximo; afirmação de suas crenças e comprovação, para estes, da existência da vida extrafísica, reencarnação, planos espirituais e divindade.

Já no caso de Bárbara/31, devido a EFC lhe ser uma experiência com alto grau de ansiedade, pois entende que pode morrer a qualquer momento, a experiência, ao contrário de reduzir sua tanatofobia, exacerbou-a, como ela mesma descreve:

Aí entra, não sei se é manias... né? Eu tenho muitas manias, do tipo: não atravessar atrás de ônibus, mas aí, é tudo no sentido relacionado a... a esse... a essa ruptura de corpo e alma, morte. Entendeu? É como se eu tivesse em vigília pra não... pra isso não acontecer (Bárbara/31)

Rodolfo/24 é o único entrevistado a apresentar maior viés psicológico que afirma que a EFC o inspirou a ser mais caridoso e preocupado com o próximo. No entanto, apresenta as consequências de tal experiência como sendo, majoritariamente, de caráter concreto, o auxiliando a ser mais centrado e dedicado em âmbitos como trabalho e estudo. Assim, aproxima-se do discurso de Mateus/35, que diz:

Eu quis ter uma estabilidade pra depois me lapidar, mesmo que eu perdesse a oportunidade. [...] Hoje se eu não pratico mais isso é porque, como eu falei, primeiro porque eu acho que, primeiro eu tenho que tá consciente aqui. A minha... experiência principal é tá consciente, aqui, falando contigo, agora. E saber que eu to consciente fazendo isso. [...] Assim, essas relações e essas frequências, pra mim, são muito mais interessantes no momento, do que eu, simplesmente, ficar sonhando e acordando no meu sonho, sei lá. A não ser que eu veja algo prático nisso (Mateus/35).

Para Flávia/33, apesar de a experiência ter grande importância, devido ao conteúdo (relação com o avô), seu entendimento de que vivera uma EFC é ainda bastante recente e enviesado por ceticismo; sendo a experiência válida, sobretudo, pela relação com a imagem do avô e não por sair do corpo. Do mesmo modo, Marcela/23, ao entender a EFC como um mero distúrbio de percepção, também não deposita sentido importante à experiência, sendo esta, apenas periférica em seu mundo fenomênico.

\section{Considerações finais}

A EFC, portanto, apresenta diversas nuances, conteúdos e sentidos, a partir da constituição de uma explicação que, segundo Merleau-Ponty (1945/2006) "não é descoberta mas inventada, ela nunca é dada com o fato, é sempre uma interpretação provável” (p. 165). Deste modo, seja real ou ilusória, a EFC compõe sentido à própria experiência e à vida do sujeito que a percebe, pois mesmo "o equívoco é essencial à existência humana, e tudo o que vivemos ou pensamos sempre tem vários sentidos" (p. 233).

Assim, por meio da variedade de EFC encontrada, é possível verificar que tais experiências podem ocorrem próximas ou distantes ao corpo físico, e constar desde sensação de flutuação e leveza, sensação de saída do corpo, alta vivacidade e consciência durante o sonho e autoscopia. Elas podem se caracterizar como experiências místicas - de cunho religioso - com presença de espíritos, podendo estar em algum local conhecido ou desconhecido; ou como experiências mundanas, ocorridas em local conhecido e sem presença de qualquer existência não física.

Deste modo, é possível questionar a real existência de um fenômeno EFC específico, sendo possível o entendimento do termo enquanto uma gama de experiências singulares, ancoradas por meio do sentido dado à experiência. Ademais, no que tange à flexibilidade de tal experiência - a qual é explicada e vivida de modos diversos a partir da crença pessoal - com relação ao entendimento da própria EFC, da função da experiência sobre o mundo fenomenológico do sujeito, tal experiência se constitui enquanto objeto importante para mais estudos acerca da percepção, crenças e relação com a vida cotidiana dos sujeitos que alegam ter tais experiências.

\section{Referências}

Alvarado, C. S. (1989). Trends in the Study of Out-of-Body Experiences: An Overview of Developments Since the Nineteenth Century. Journal of Scientific Exploration, 3 (1), 27-42.

Alvarado, C. S. (2004). Out-of-body Experiences. In E. Cardeña, S. J. Lynn \& S. Krippner (orgs.), Varieties of Anomalous EXperience: Examining the Scientific Evidence (p. 183-218). Washington, DC: American Psychologial Association.

Blackmore, S. J. (1982). Beyond the body: An investigation of out-of-the-body experiences. London: Heinemann. 
Blackmore, S. J. (1984). A psychological theory of the out-of-body experience. Journal of Parapsychology, 48, 201-218.

Blanke, O. \& Arzy, S. (2005). The out-of-body experience: Disturbed self-processing at the temporo-parietal junction. Neuroscientist, 11(1), 16-24.

Blanke, O., Ortigue, S., Landis, T., \& Seeck, M. (2002). Stimulating illusory own-body perceptions. Nature, 419 (6904), 269-270.

Creswell, J. W. (2012). Qualitative inquiry and research design: Choosing among the five traditions. Thousand Oaks, CA: Sage

De Foe, A. (2012). How Should Therapists Respond to Client Accounts of Out-of-Body Experience? International Journal of Transpersonal Studies, 31 (1), 75.82

De Ridder D., Van Laere K., Dupont P., Menovsky T., \& Van de Heyning P. (2007). Visualizing out-of-body experience in the brain. New England Journal of Medicine, 357 (18), 1829-33.

Freitas, M. H., Araújo, R. C., Franca, F. S. L., Pereira, O. P. \& Martins, F. (2012). Os Sentidos do Sentido: Uma Leitura Fenomenológica. Revista da Abordagem Gestáltica, XVIII(2), 144-154.

Gomes, W. B. (2010). Relações metodológicas entre fenomenologia, historiografia e psicologia humanista. Revista da Abordagem Gestáltica, 16 (1), 3-11.

Holt, N. J., Simmonds-Moore, C., Luke, D., \& French, C. C. (2012). Anomalistic Psychology. London: Palgrave.

Irwin, H. J. (1985). Flight of Mind: a psychological study of the out-of-body experience. Metuchen, New Jersey: The Scarecrow Press.

Merleau-Ponty, M. (2006). A Estrutura do Comportamento. (M. V. M. Aguiar, Trad.). São Paulo: Martins Editora. (Trabalho original publicado em 1942)

Merleau-Ponty, M. (2006). Fenomenologia da Percepção. (3. ed.). (C. A. R. Moura, Trad.). Editora Martins Fontes. (Trabalho original publicado em 1945)

Merleau-Ponty, M. (2003). O visível e o invisível. (4 $4^{\mathrm{a}}$ edição). (J. A. Gianotti \& A. M. Oliveira, Trad.). São Paulo: Perspectiva.

Moustakas, C. (1994) Phenomenological research methods. Thousand Oaks, CA: Sage.

Myers, F.W.H. (1903). Human Personality and Its Survival of Bodily Death. New York: Longmans, Green and Co.

Neppe, V. (2011). Models of the Out-of-Body Experience: A New Multi-Etiological Phenomenological Approach. NeuroQuantology, 9 (1), 72-83.

Osty, E. N. (1930). La vision de soi. Revue métapsychique, No. 3, 185-197

Palmer, J. (1978). The out-of-body experience: A psychological theory. Parapsychology Review, 9 (5), 19-22.

Patton, M. Q. (1990). Qualitative Evaluation and Research Methods. Newbury Park, CA: Sage Publications.

Penfield, W. (1958). Functional localization in temporal and deep Sylvian areas. Research Publications Association for Research in Nervous and Mental Disease, 36 (1): 210-26.
Persinger, M.A. (1999). Near-death experiences and ecstasy: A product of the organization of the human brain? In S. Della Sala (Ed.), Mind myths: Exploring popular assumptions about the mind and brain (p. 85-99). New York: Wiley.

Spiegel, D. \& Cardeña, E. (1991). Disintegrated experience: the dissociative disorders revisited. Journal of Abnormal Psychology, 100 (3): 366-378.

Tart, C. T. (1968). A psychophysiological study of out-of-body experiences in a selected subject. Journal of the American Society for Psychical Research, 62, 3-27.

Tart, C. (1975). Transpersonal Psychologies. New York: Harper \& Row.

Tart, C. T. (1976). A second psychophysiological study of out-of-body experiences in a gifted subject. International Journal of Parapsychology, 9, 251-258.

Wettach, G.E. (2000). The near-death experience as a product of isolated subcortical brain function. Journal of Near Death Studies, 19, 71-90.

Whiteman J. H. M. (1980). Separative experience. Psi, 2 (1), 1-4.

Whiteman, J. H. M. (2006). Old and New Evidence on the Meaning of Life. Volume 3. Universal Theology and Life in the Other Worlds. Gerrards Cross: Colin Smythe.

Whitlock, F.A. (1978). The psychiatry and psychopathology of paranormal phenomena. Australian and New Zealand Journal of Psychiatry, 12 (1): 11-9.

Gabriel Teixeira de Medeiros - Possui Graduação em Psicologia e Mestrado em Ciências Interdisciplinares da Saúde pela Universidade Federal de São Paulo (UNIFESP). É membro do Grupo de Pesquisa CNPq UNIFESP-USP: Corpo e Alma do Sujeito da Saúde (CASUSA). Membro do Laboratório de Pesquisa Social e do Grupo de Pesquisa - CNPq UNIFESP-UFSCar: Corpo, cognição e experiência nas ciências da mente e membro do INTER PSI - Laboratório de Psicologia Anomalística e Processos Psicossociais (USP). Endereço Institucional: Universidade Federal de São Paulo, Departamento de Políticas Públicas e Saúde Coletiva. Rua Silva Jardim, 136 (Térreo), Vila Matias. CEP 11015.020 - Santos, SP. E-mail: gabriel-tmedeiros@yahoo.com

Fernando de Almeida Silveira - Advogado e Psicólogo, com Formação e Mestrado pela Universidade de São Paulo, e Pós-Doutorado em Filosofia pela Universidade Federal de São Carlos (UFSCar). É Professor Adjunto IV (Psicologia e Humanismo) da Universidade Federal de São Paulo - Campus Baixada Santista - Departamento de Políticas Públicas e Saúde Coletiva. Coordena do Grupo de Pesquisas CNPq/UNIFESP/USP Corpo e Alma do Sujeito da Saúde (CASUSA); Membro do Laboratório de Pesquisa Social e do Grupo de Pesquisa Corpo, Cognição e Experiência nas Ciências da Mente (CNPq-UNIFESP-UFSCar), e Co-Responsável pelo Núcleo de Estudos sobre Fenomenologia, Psicologia e Epistemologia. E-mail: fernandos.unifesp@gmail.com

Recebido em 13.08.2013 Primeira Decisão Editorial em 30.01.2014 Nova Submissão em 03.06.2014 Aceito em 12.12.2015 